\title{
Role of innate immune response in non-alcoholic fatty liver disease: metabolic complications and therapeutic tools
}

\section{Rosaria Meli *, Giuseppina Mattace Raso and Antonio Calignano}

Department of Pharmacy, University of Naples "Federico II," Naples, Italy

\section{Edited by:}

Oreste Gualillo, Santiago University Clinical Hospital, Spain

\section{Reviewed by:}

Silvana Gaetani, Sapienza University of Rome, Italy

Massimo Collino, University of Turin Italy

\section{*Correspondence:}

Rosaria Meli, Department of Pharmacy, University of Naples "Federico II,"Via D. Montesano 49, Naples 80131, Italy

e-mail:meli@unina.it
Non-alcoholic fatty liver disease (NAFLD) is currently the most common liver disease worldwide, both in adults and children. It is characterized by an aberrant lipid storage in hepatocytes, named hepatic steatosis. Simple steatosis remains a benign process in most affected patients, while some of them develop superimposed necroinflammatory activity with a non-specific inflammatory infiltrate and a progression to non-alcoholic steatohepatitis with or without fibrosis. Deep similarity and interconnections between innate immune cells and those of liver parenchyma have been highlighted and showed to play a key role in the development of chronic liver disease. The liver can be considered as an "immune organ" because it hosts non-lymphoid cells, such as macrophage Kupffer cells, stellate and dendritic cells, and lymphoid cells. Many of these cells are components of the classic innate immune system, enabling the liver to play a major role in response to pathogens. Although the liver provides a "tolerogenic" environment, aberrant activation of innate immune signaling may trigger "harmful" inflammation that contributes to tissue injury, fibrosis, and carcinogenesis. Pathogen recognition receptors, such as toll-like receptors and nucleotide oligomerization domain-like receptors, are responsible for the recognition of immunogenic signals, and represent the major conduit for sensing hepatic and non-hepatic noxious stimuli. A pivotal role in liver inflammation is also played by cytokines, which can initiate or have a part in immune response, triggering hepatic intracellular signaling pathways. The sum of inflammatory signals and deranged substrate handling induce most of the metabolic alteration traits: insulin resistance, obesity, diabetes, hyperlipidemia, and their compounded combined effects. In this review, we discuss the relevant role of innate immune cell activation in relation to NAFLD, the metabolic complications associated to this pathology, and the possible pharmacological tools.

Keywords: NAFLD, insulin resistance, pathogen recognition receptors, innate immune cells, cytokines, inflammation, DAMPs, pathogen-associated molecular patterns

\section{INTRODUCTION}

Non-alcoholic fatty liver disease (NAFLD) represents a wide range of pathologies beginning with simple triglyceride accumulation inside the hepatocytes, a benign condition that can evolve and progress to non-alcoholic steatohepatitis (NASH), characterized by inflammation and hepatocytes injury. Disease progression occurs together with metabolic and inflammatory derangements that accompanied by genetic and environmental factors, promote a persistent activation of the immune system. A complex backdrop involves adipokines, metabolites [i.e., free fatty acids (FFAs)],

Abbreviations: AMPK, AMP-activated protein kinase; DAMPs, damage-associated molecular pattern; FFAs, free fatty acids; HOMA-IR, homeostatic metabolic assessment-insulin resistance; HSCs, hepatic stellate cells; IR, insulin resistance; KC, Kupffer cells; LPS, lipopolysaccharide; NAFLD, non-alcoholic fatty liver disease; NASH, non-alcoholic steatohepatitis; NLRs, NOD-like receptors; NOD, nucleotide oligomerization domain; PAMPs, pathogen-associated molecular patterns; PPAR, peroxisome proliferator-activated receptor; PRRs, pathogen recognition receptors; ROS, reactive oxygen species; TGF, transforming growth factor; TIR, Tollinterleukin-1 receptor; TLRs, toll-like receptors; TRIF, TIR-domain-containing adapter-inducing interferon- $\beta$; UCP, uncoupling protein. cell-derived fragments, all released by damaged cells and metabolic disrupted organs, such as liver and adipose tissue $(1,2)$. The innate immune system that in physiological condition maintains tissue and organ homeostasis, may undergo an aberrant activation, and trigger harmful inflammation, which contributes to initially low-grade inflammation, tissue and organ injury, and lately fibrosis and carcinogenesis (3). A key role in the pathogenesis of NAFLD is played by gut-derived endotoxin, a component of the Gram-negative bacteria wall, which reaches the liver when the colonic mucosa is disrupted. Together with lipopolysaccharide (LPS), other bacterial products, such as lipoproteins, flagellins, and peptidoglycans termed pathogen-associated molecular patterns (PAMPs), share or not similar molecular structures.

Pathogen recognition receptors (PRRs), such as toll-like receptors (TLRs) and nucleotide oligomerization domain (NOD)-like receptors (NLRs), are responsible for the recognition of immunogenic signals, representing a major conduit for alterations in liver. The various types of TLRs enables to discriminate between different PAMPs that belong to several microbial classes For instance, TLR4 is able to recognize LPS from Gram-negative bacteria, while 
TLR2 detects Gram-positive bacteria through the recognition of cell membrane components, i.e., lipoteichoic acid, peptidoglycan, and various lipopetides and lipoproteins, while other TLRs, such as 3 and 7, sense viral infection binding double- and single-stranded RNA (4). Therefore, these receptors recognized more than one ligand, binding even completely structural different molecules (5). The activation of TLRs does not occur in physiological conditions, conversely, when an environmental change induces tissue injury and cell dying, endogenous protein, and non-protein ligands, named damage-associated molecular pattern (DAMPs) or alarmins (6) can bind to TLRs and induce their activation. DAMP sources include heat shock proteins, high mobility group box 1, breakdown products of the extracellular matrix (i.e., hyaluronan, fibrinogen, and fibronectin), and non-protein substrates (5-7). Also NLRs are able to recognize PAMPs and DAMPs, and are expressed mainly on antigen-presenting cells and epithelial cells. NLRs activation leads to the assembly of the inflammasome, containing caspase-1, whose activation leads to inflammation and apoptosis. Caspase-1, in fact is also known as interleukin cleavage enzyme, responsible for the conversion of prointerleukin-1, -18 , and -33 in the respective mature forms. The activation of PRRs leads to cytokine production, contributing to liver injury and metabolic complications. In particular TNF $\alpha$ and IL-6, originally considered classical inflammatory cytokines, are now considered major links between steatosis, insulin resistance (IR), and related inflammatory disorders. Indeed, it has been demonstrated that $\mathrm{TNF} \alpha$ reduced insulin signaling activation (8) and its expression in liver is enhanced in patients affected by $\operatorname{NAFLD}(9,10)$. Also IL-6 has been implicated in IR, in fact is now considered its predictor or pathogenetic marker. Moreover its expression correlates with the degree of hepatic inflammation, and fibrosis $(9,11)$. Recent studies in mouse models of NASH implicate caspase- 1 and inflammasome in inflammatory response associated to metabolic complications $(12,13)$. Therefore, metabolic systems are closely integrated with downstream pathway of TLRs and NLRs. Upon pathogens sensing by the innate immune system, concomitantly insulin signaling and inflammatory response are modulated as a result of the activation of PPRs pathways, triggering both immunological and metabolic processes $(14,15)$.

\section{GUT-LIVER AXIS}

The anatomical site and cellular architecture of the liver make it a key organ in metabolic essential functions. The position between gut and systemic circulation, guarantees that all the substances orally ingested and absorbed by the intestine have to necessarily pass to the liver. As a result, the liver has developed the ability not only to receive, process, and store substances, as it occurs in case of nutrients, but also to respond to exogenous antigenic molecules (i.e., food, viral, bacterial, and parasitic substances). Therefore, the liver, originally considered only a metabolic organ, is now recognized as a mediator of systemic and local innate and adaptive immunity. Indeed, it is continuously exposed to antigens from the gut through the portal vein since sinusoidal endothelial cells of liver parenchyma are characterized by the lack of the basement membrane. Moreover, the liver contains a specialized cellular repertoire able to degrade and remove toxins, exogenous antigens, and infectious agents. This expertise allows to achieve an immune tolerance, avoiding overactivation of immune system or, conversely, to switch the tolerant response to a responsive state when demanded (16-21). Therefore, the status of gut integrity strictly accounts for the exposure of liver to gut microbiota and antigenic food components. Translocation of large amounts of gut-derived products is usually prevented by intact barrier systems provided by intestinal epithelial cells (22). When the disruption of intestinal barrier results in leaky gut, bacteria and bacterial products easily migrate to the mesenteric lymph nodes and to the liver. This bacterial translocation may impair liver homeostasis and trigger liver inflammation, inducing the innate immune response $(3,22,23)$.

\section{INNATE IMMUNITY AND CELL INVOLVEMENT IN NAFLD: ROLE OF CYTOKINES}

Apart from parenchymal hepatocytes, the liver also contains complex repertoires of lymphoid and non-lymphoid cells, key effectors for hepatic immunoregulation, and defense $(16,21)$.

Hepatic lymphoid cells comprise resident lymphocytes, distinct both in function and phenotype, from their counterparts in the peripheral circulation and in other organs. In particular, liver hosts conventional (i.e., B cells, CD4+ and CD8+ T cells, natural killer cells) and non-conventional lymphoid cells (i.e., $\gamma \delta$ TCR + T cells, natural killer T cells, CD4- and CD8- T cells). A key role in specific immune function is also exerted by mucosalassociated invariant $\mathrm{T}$ cells that are a highly specialized $\mathrm{T}$ cell population in the vascular network of the liver (24). Regulatory T cell populations seem to have an important role in maintaining a beneficial balance in the liver between immuno-tolerance and activation (25). In addition to classic parenchymal hepatocytes and cholangiocytes, the liver contains other cell types responsible for the homeostasis of the innate and adaptive immune system. Among the non-lymphoid cells, Kupffer cells (KC) (26) and dendritic cells $(27,28)$ from the myeloid lineage have a major role in the immune response. Dendritic cells are the primary antigenpresenting cells of the liver. However, cholangiocytes can also act as antigen-presenting cells (29), thus playing an additional role in the hepatic immune function.

\section{KUPFFER CELLS}

Resident- or monocyte-derived $\mathrm{KC}$ are the largest population of mononuclear phagocytes in the body. They are present throughout the liver, but there is variation in the population density, cytological characteristics, and physiologic functions of $\mathrm{KC}$ in different zones of the hepatic acinus/lobule (30). During liver injury and diseases, monocytes rapidly differentiate into mature cells that are indistinguishable from genuine $\mathrm{KC}$, independently from the circulating monocytes (31). They are strategically located in liver sinusoids, therefore they come firstly in contact with exogenous immunoreactive material or endogenous signals (32) phagocytosing, processing and presenting antigen, and secreting various pro-inflammatory mediators such as cytokines, prostanoids, nitric oxide, and reactive oxygen intermediates (33). Expression of the Fc receptor results in non-specific phagocytosis of immune complexes as well as antibody-coated particles such as microorganisms and allows $\mathrm{KC}$ to have a significant role in control of inflammatory and immunologic processes (34). Moreover, $\mathrm{KC}$ also express 
complement receptors for binding and phagocytosis. Bacterial endotoxin derived from the gut or endotoxin injected in rodents are cleared principally by the liver and taken up primarily by KC (35). Within the liver, LPS binds to LPS-binding protein, which then facilitates the transfer of LPS to CD14 on the surface of KC. Signaling of LPS through CD14 is mediated by the downstream TLR4, resulting in activation of $\mathrm{KC}$ and direct involvement of the innate immune system (36). Also TLR2 has a key role in KC response to insults, in fact TLR2-deficient $\mathrm{KC}$ showed an impaired response toward microbes, such as Listeria monocytogenes (37). After activation, $\mathrm{KC}$ can either avoid escalation of inflammatory response, through a fine control of adaptive immune, or vice versa failure to halt inflammation, properly recognizing and eliminating danger molecules.

Generally, KC are exposed to low gut-derived LPS levels. This stimulus allows $\mathrm{KC}$ to trigger an escape mechanism that involves IL-10, which in turn contributed to the down-regulation of pro-inflammatory cytokines (38). On the other hand, following massive TLR4 stimulation, KC produce several chemokines and cytokines, such as TNF $\alpha$, IL-1 $\beta$, IL-6, IL-12, and IL-18 $(39,40)$. IL-12 and IL-18, in particular, can induce IFN- $\gamma$ production by NK cells, facilitating microbial eradication, and hepatic wound healing (41). Thus, KC may have a higher tolerance to LPS, or a prompt inflammatory response, adapting to the contingent circumstances. To maintain the steady state, $\mathrm{KC}$ are able to mount opposite responses to exogenous triggers, polarizing to M1 or M2 subphenotypes (42). In response to TLR ligands and cytokines, KCs undergo polarized inflammatory programs, known as M1 (classical) or M2 (alternative) activation. While the M1 phenotype is characterized by the increase in the production of inflammatory cytokines, and reactive nitrogen and oxygen species, associated by microbicidal and tumoricidal activity, M2 macrophages show immunomodulatory functions, parasite containment, and tissue remodeling. Similarly to $\mathrm{M} 1$ phenotype, $\mathrm{KC}$ can contribute to the pathogenesis of liver disease, increasing the production of proinflammatory cytokines (e.g., TNF $\alpha$ ) (17, 42, 43). Conversely, adiponectin was recently shown to shift $\mathrm{KC}$ polarization to the M2/anti-inflammatory phenotype $(44,45)$, preventing progression of NASH in mice (46). Adiponectin decrease, as well as adiponectin gene deletion, induces hepatic steatosis progression, fibrosis, and tumor development (47). Moreover, KCs have also metabolic function, regulating fatty acids oxidation, increasing hepatic lipid storage and IR, as mechanisms of adaptation to increased caloric intake (48). This event is triggered by the secretion of inflammatory cytokines (i.e., TNF, IL-6, IL-1 $\beta$ ) (48), thus suggesting a beneficial role for alternatively M2-activated KCs in metabolic derangements $(49,50)$.

\section{HEPATOCYTES}

Hepatocytes exert metabolic and detoxifying functions, and prompt the acute phase response. They express TLR4, even if high doses of LPS are needed to induce significant effects (51, 52). Their expression of TLR2, rather than TLR4, is up-regulated in inflammatory conditions, suggesting a major responsiveness to TLR2 activation following an insult (52). Hepatocytes are able to clear LPS from systemic circulation, through its uptake and release into the bile, more than $\mathrm{KCs}$, since $\mathrm{KC}$-depleted rats have the same capacity of LPS removal (53). TLR4, CD14, and myeloid differentiation (MD)-2 have an obligatory role for LPS uptake by hepatocytes. Nevertheless, TLR4 signaling does not seem to be required for this process in vivo (54).

\section{HEPATIC STELLATE CELLS}

Hepatic stellate cells (HSCs) include around 30\% of the nonparenchymal cells (55). In physiological conditions, HSCs are quiescent cells, and represent the largest content of vitamin A in the body (56). When the liver is injured, damaged hepatocytes and immune cells start to release signal molecules that, targeting HSCs, induce their trans-differentiation into activated myofibroblast-like cells $(55,57,58)$. Therefore, activated HSCs switch from resting vitamin A-rich cell to proliferating, fibrogenic, and contractile cell $(58,59)$, leading to hepatic fibrosis. The main activators of their trans-differentiation are plateletderived growth factor and transforming growth factor (TGF)- $\beta 1$, produced by activated $\mathrm{KC}$, infiltrating monocytes, platelets, and damaged hepatocytes (60). The resting HSCs may acquire adipogenic or myogenic phenotype during the trans-differentiation (61), determined by adipogenic and myogenic gene expression. In fact, adipogenic genes are down-regulated under ischemia and inflammation and up-regulated by peroxisome proliferatoractivated receptor (PPAR) $\gamma$. Conversely, activated HSCs, expressing myogenic genes, can develop a myofibroblast-like feature, and release extracellular matrix components, including fibrillar collagens (collagen I and III) (62). Moreover, HSCs can also produce tissue inhibitors of metalloproteinases, which may reduce extracellular matrix components degradation, decreasing matrix metalloproteinases (MMPs) activities.

In addition to TGF- $\beta 1$, other factors are implicated in HSCs activation to become myofibroblastic, such as the Hedgehog ( $\mathrm{Hh})$ pathway (63), cytokine stimulation (particularly TNF- $\alpha$, IL-1 $\beta$, and IL-6) (64), and leptin (65). Leptin, a well-recognized profibrotic hormone, activates JAK2/STAT3 pathway following the binding of its hepatic functional receptor, and increases the expression of tissue inhibitors of metalloproteinases, leading to matrix deposition. Moreover, it also inhibits matrix degradation, reducing MMPs expression (66). In fact, leptin receptor expression is low in quiescent HSCs, but increases during their transdifferentiation (67). Conversely, adiponectin released from adipose tissue reduces HSC migration and proliferation (67). Accumulating evidence indicates that a role in HSC activation is also played by renin-angiotensin system expressed in injured liver. In particular, HSCs generate de novo angiotensin 2 (68) that increases HSC proliferation and migration, cytokine and collagen synthesis (69, 70). Finally, TLR4 contributes to the activation of HSCs through an MyD88-NF-кB-dependent pathway $(3,71)$. HSCs activation in NASH have been already reported (72), however, more studies are needed to better clarify its role in NAFLD onset and progression.

\section{BILIARY EPITHELIAL CELLS}

Biliary epithelial cells lined the biliary tree, which carries the bile into the intestine. As for HSCs, recently it has been demonstrated a role for biliary epithelial cells in portal and septal fibrosis (73). Murine biliary cells express CD14, MD-2, and TLR2, 3, 4, and 5 (74). After LPS stimulation, murine biliary cells activates the 
NF- $\mathrm{KB}$ pathway and synthesized TNF $\alpha$ (74). After TLR2 and TLR4 activation, CDX2 and mucus core protein-2 expression increased (75). Human biliary epithelial cells express TLR1-10 $(76,77)$. The progression of NAFLD in humans has been related to the increase in bile ductules, and their senescence markers. Moreover, such senescent bile ductules expressed chemotactic protein, such as MCP-1, likely responsible for HSC activation (73).

\section{HEPATIC DENDRITIC CELLS}

Hepatic dendritic cells are the antigen-presenting cells in the liver. In inflammatory conditions, they are recruited into liver sinusoids, and migrate to periportal and pericentral areas. They express TLR4/MD-2 complex, produce inflammatory cytokines (i.e., IL-12 and $\mathrm{TNF} \alpha$ ), and express co-stimulatory molecules (CD40, CD80, and CD86) following several stimuli, such as LPS, peptidoglycan, poly-I:C, and cytidine-phosphateguanosine (CpG)-DNA (3). De Creus et al. (78) found a lower expression on TLR4 in hepatic dendritic cells compared to the spleen counterparts, suggesting a reduced activation of hepatic adaptive immune response; on the other hand an higher expression of TLR2 and TLR4 was shown in hepatic dendritic cells, related to an increased production of TNF $\alpha$ and IL-6 after LPS and peptidoglycan stimulation (79).

\section{SINUSOIDAL ENDOTHELIAL CELLS}

Sinusoidal endothelial cells have a major role in hepatic perfusion and supply, constituting the fenestrated lining of liver sinusoids. These cells constitutively express TLR4 and CD14 and, if acutely stimulated with LPS, NF- $\mathrm{KB}$ activation occurs. Conversely, repetitive challenge with LPS induces a reduced activation of NF-KB pathway in these cells, associated with a reduction of CD54 expression and leukocyte adhesion (80). TLR1-9 mRNA was found in sinusoidal endothelial cells and functional expression of TLR3 has been demonstrated in controlling hepatitis B virus replication by non-parenchymal liver cells (81). The role in LPS uptake is somewhat controversial, since contrasting data were obtained $(53,82)$.

\section{PRRS: TLRs AND NLRS IN LIVER}

The innate immune system is the major contributor to acute inflammation induced by microbial infection or tissue damage (83). Currently, 10 and 12 members of the TLR family have been identified and ubiquitously expressed in humans and mice, respectively. While TLRs sense PAMPs and DAMPs at the cell surface or in endosomes, NLRs monitor the cytosolic compartment. TLRs, so named for their similarity to a protein coded by Toll-gene in the fruit fly of Drosophila, recognize signature motifs, PAMPs, through a conserved ectodomain with leucine rich repeats, resulting in an alertness of immune system to the presence of microbial antigens (84).

Being widely expressed in hepatic cells, TLRs can detect a range of microbial structures, promoting innate and adaptive immune responses against detected pathogens (84-87). Their signaling in the liver is associated with pathological implications in a wide range of acute or chronic liver disease. The specific recognition, rather than non-specific as previously recognized, by TLRs was discovered in mid-1990s and rewarded later by the Medicine Nobel Prize laureates Bruce A. Beutler and Jules A. Hoffmann. Physiologically, TLR signaling induces protective responses, such as pathogen clearance, regenerative mechanisms, and protection from cell death. Abnormal TLR signaling is associated to hepatic damage, endotoxin shock, organ failure, impairment of regenerative responses, fibrosis, and hepatocarcinoma (88-90).

Toll-like receptors are type I transmembrane proteins containing, a part from pathogen recognition domain, transmembrane domains, and intracellular Toll-interleukin-1 receptor (TIR) domains required for signaling transduction. Binding of TLRs leads to activation of multiple pathways from an intracellular signaling cascade, transcription of inflammatory genes, synthesis of inflammatory cytokines and interferons, and cell recruitment. It also stimulates expression of co-stimulatory molecules required to induce an adaptive immune response of antigen-presenting cells (66). However, evidence on mice deficient in each TLR has demonstrated distinctive functions of these receptors in terms of PAMP recognition and immune response (87). Microbial recognition by TLRs occurs in several cellular compartments, such as plasma membrane, endosomes, lysosomes, and endolysosomes. The localization and trafficking of TLRs within the cell is important for ligand accessibility, tolerance of self-molecules, and downstream signaling transduction (84). In fact, TLRs can be grouped into two divisions based on their subcellular localization. TLR1, 2, 4,5 , and 6 are found to be on the cell surface, while TLR 3 , 7,8 , and 9 are located intracellularly and are nucleic acid sensing (91). The majority of TLR family members associate with MyD88, a common adaptor molecule, through the TIR domains, triggering inflammatory pathways. Conversely, TLR3 and TLR4 bind another adaptor protein, TIR-domain-containing adapterinducing interferon- $\beta$ (TRIF), to induce type I IFN. In order to recognize LPS, TLR4 needs to recruit LPS-binding protein, CD14, and myeloid differentiation MD-2. After TLR4 binding, the intracellular domain of TLR4 recruits TIR-domain-containing adapter protein and MyD88 for MyD88-dependent signaling, and TRIFrelated adaptor molecule binds TRIF for MyD88-independent signaling $(83,92)$. TLR role, in the context of NAFLD/NASH onset and progression, has been particularly addressed for TLR4, TLR2, and $\operatorname{TLR} 9(93,94)$.

TLR4 has been particularly studied in relation to inflammation and fibrogenesis in liver (3). Here, KC, hit by bacterial or sterile insults, contribute through TLR4 activation to many liver diseases including diet-induced liver insults. Binding of LPS to TLR4 on KC, activating NF-kB, MAPK, ERK1, p38, JNK, and IRF3, induces the production of inflammatory cytokines and type I IFN, contributing to tissue damage, increase in leukocyte infiltration, and secretion of profibrogenic cytokines. In fact inactivation of TLR4 leads to attenuation of steatosis and NASH in several models of experimental models $(95,96)$. Beyond TLR4, also TLR9 signaling, induced by nuclear DNA activation, has been implicated in NASH. This receptor in fact is able to bind CpG oligonucleotides, contained by DNA from gut-derived bacteria. Noteworthy, bacterial DNA was detectable in blood from mice with diet-induced NASH (93). Moreover, TLR9-/- mice were sheltered from NASH, and this protection was related to a decrease in IL- $1 \beta$ production by KC (93). TLR9 detrimental effect on liver was ascribed to bone-marrow-derived cells, since mice transplanted with TLR9deleted bone marrow were protected by liver injury (97). TLR9 protective effect was also confirmed in other types of liver injury, 
such as I/R damage, using an inhibitory CpG sequence (97) or in acetaminophen-induced hepatocyte death, using TLR9 antagonists (98). On the other hand, TLR9 can also mediate injurylimiting pathways. It has been shown that TLR9 is involved in dendritic cells response to DNA released from cell damage. In particular, dendritic cells respond to DAMPs through the production of the anti-inflammatory IL-10 (97).

Lipopolysaccharide and other gut-derived bacterial products, secondary to bacterial translocation, can stimulate TLR in the liver (99). In this context, activation of TLRs, placed on the different hepatic cell populations, results in acute and chronic liver diseases. Evidence clearly showed a pivotal role for TLRs, gut microflora, and bacterial translocation in NASH and fibrosis. Gut microbiota has shown to modify metabolic parameter and glucose homeostasis in TLR2 knockout mice. In fact these mice acquired a phenotype reminiscent of metabolic syndrome characterized by differences in the gut microbiota (100). Moreover, the gut microbiota modifications observed were related to an increase in LPS absorption, low-grade inflammation, glucose intolerance, IR, and obesity. Interestingly, the molecular mechanisms associated to these effects involved activation of TLR4, endoplasmic reticulum stress, and activation of JNK (100).

Autophagy, a lysosome-dependent process of self-eating, has recently considered as a key regulatory pathway of the innate immune response, through effects on TLRs (101). It has been demonstrated that Atg16L1, an autophagy gene associated with susceptibility to inflammatory bowel disease, mediating autophagosome formation regulates LPS-induced intestinal inflammation. Consistently, macrophages lacking Atg16L1 produced increased amounts of the pro-inflammatory cytokines IL$1 \beta$ and IL-18 in response to LPS stimulation (102). Hence, failure in macrophage macroautophagy may sustain hepatic steatosis and liver damage. Activation of macroautophagy increases the turnover of damaged proteins, peroxisomes, and mitochondria (103), reducing accumulation of harmful molecules. However, it is not known whether the impairments in autophagy, revealed in fatty livers, involve only hepatocytes or also KC. Indeed, in steatotic liver, the suppression of autophagy in KCs increases the sensitivity to endotoxin, suggesting a protective effect of autophagy on progression of NAFLD (104). PAMPs and DAMPs can also be recognized by NLR $(105,106)$, whose activation leads to the formation of so called inflammasome. Twenty-two NLR genes have been identified in humans thus far. The first discovered NLRs are NOD containing proteins NOD1 and NOD2, which sense bacterial peptidoglycan. Specifically, NOD1 recognizes the mesodiaminopimelic acid found predominantly in Gram-negative bacteria, whereas NOD2 detects the muramyl dipeptide present in all bacteria. NOD1/2 activation signals through MAPKs and NF-kB and induces transcriptional up-regulation of pro-inflammatory cytokines (83). Because NOD1 can recognize peptidoglycan from the gut microbiota (107), it is possible that nutrient excess is sensed by NOD1 through alteration of the gut microbiota and enhanced translocation of peptidoglycan. Several NLR members, i.e., NLRP1, NLRP3, NLRP6, and NLRC4, assemble into large multiprotein complexes called inflammasomes to control caspase-1 activity (108). Inflammasomes are sensors of endogenous or exogenous PAMPs or DAMPs that govern cleavage of effector pro-inflammatory cytokines (109). After a priming step, such as infection or injury, there is an increase in inflammasome expression, which is then triggered by PAMPs or DAMPs (110). Therefore, the inflammasome constitutes a platform for the activation of caspase-1, leading to maturation of IL- $1 \beta$ and IL-18 and inactivation of IL-33, regulating cell survival and death (111).

In general, activation of TLRs and NLRs induces the production of pro-inflammatory cytokines and the recruitment of immune cells, such as macrophages and T lymphocytes, in the liver, as well as other tissues, including adipose tissue, muscle, hypothalamus, pancreatic islets, and blood vessels. The resultant chronic lowgrade inflammatory state promotes IR and energy imbalance and contributes to the metabolic complications of obesity, such as fatty liver disease, T2D, and atherosclerosis. The inflammasome activation has been involved in NAFLD. In particular, saturated fatty acids induce a sensitization to LPS-induced inflammasome activation and hence liver injury. As a matter of fact, dangerous signals are released by hepatocytes, contributing to inflammasome activation in immune cells (112). A critical determinant in the progression of NFLD toward NASH is the modulation of intestinal microbiota through multiple inflammasome components. Among NLR members, the NLRP3 inflammasome has also been demonstrated to play a critical role in diet-induced obesity and IR. Multiple studies using mice deficient in different components of the NLRP3 inflammasome (NLRP3 and caspase-1) have consistently shown that loss of the NLRP3 inflammasome decreases HFD-induced hepatic steatosis and inflammation (113) and improves systemic insulin sensitivity $(12,13,114,115)$. NLRs/inflammasomes play a role in the pathogenesis of steatosis/steatohepatitis induced in several experimental models through alcohol (116), acetaminophen (98), liver I/R injury $(117,118)$, or LPS $(119,120)$.

\section{METABOLIC COMPLICATIONS AND PHARMACOLOGICAL TOOLS}

A fine regulated interaction between immunity and metabolic system exists (14). Some tissues, such as liver and adipose tissue, have preserved their analogy of structure during the evolutionary process and show a specific organization of metabolic and cellular components responsible for a direct and rapid entry into blood vessels (121).

Liver and immune system can regulate metabolic and immune functions by common regulatory molecular pathways and pathogen-sensing systems. Among these, lipid-related pathways and TLR4-NF-к $\beta$ pathway play a major role; both are activated by metabolic, nutritional, and immunological stimuli, and can influence and regulate energy balance and IR in response to changes in nutritional environment and inflammatory status $(5,122,123)$.

Many observations point out a fine balance between immune and metabolic systems, identifying a main role for liver. The dysfunction between these two systems is unsafe and triggers the development of several pathologies. Overnutrition and obesity impair metabolic homeostasis, cause stress, and arise inflammatory process $(124,125)$, contributing to the development of the obesity-related inflammatory diseases. Conversely undernutrition and malnutrition suppress immune system and increase susceptibility to infections (14). 
The condition sine qua non of NAFLD onset is macrovesicular steatosis or fatty liver, characterized by cellular accumulation of fat, mainly in the form of triglycerides, and sustained and amplified by the inflammatory process. The accumulation and metabolism of lipid in hepatocytes is under control of insulin or other hormones and factors that act in autocrine and paracrine manner. In particular, insulin potently inhibits hepatic endogenous glucose production, which results compromised in patients with hepatic IR (126). With its role in promoting glucose uptake, insulin has long been considered a regulator of triglyceride catabolism by inhibiting hormone sensitive lipase. Moreover, another important action of insulin is its anti-lipolytic effect in adipose tissue, which is impaired in IR, inducing an elevated release and amount of FFAs into the bloodstream. However, IR is very common in NAFLD in obese and diabetic subjects, but it has been evidenced also in nonobese and non-diabetic patients (127). However, NAFLD presents IR either in liver, impairing glucose metabolism (128), or in adipose tissue, increasing lipolysis and circulating FFAs (127). All these metabolic alterations are more evident and profound in diabetic patients, who are commonly characterized by an increase of hepatic and visceral fat and IR (129).

To date, on the basis of NAFLD pathophysiology, three therapeutic targets have been identified. The first two are metabolic approaches, regarding IR and dyslipidemia, while the third is focused on oxidative stress buffering. It is conceivable that insulin sensitizers might reverse not only IR, but also liver damage observed in NAFLD. Among these, the antidiabetic drug metformin is known to reduce hepatic glucose production and increase glucose uptake in the muscle (130). Anyway, the beneficial effects of this drug on serum ALT and liver damage do not seem to be better than those obtained from lifestyle modifications (131). Beyond metformin, the second generation thioglitazones that act as agonists of PPAR $\gamma$, improve insulin sensitivity and may be considered therapeutic tools for NASH, as they are able to increase FFAs storage in subcutaneous adipocytes rather than liver and visceral fat. Moreover, they downregulate NF-kB and increase adiponectin levels (132). Anyway, even if safer than first generation drugs, thioglitazones are contraindicated in pediatric patients or in the presence of active liver disease. Furthermore, another limit is their lifelong treatment, and the possibility that, following drug cessation, steatosis might recur (133).

Drugs used in the treatment of hyperlipoproteinemias, including statins and fibrates, have been suggested beneficial in NAFLD patients, reducing the degree of hepatic steatosis but not the liver enzymes (134).

The concept of lipotoxicity and involved lipid species has been discussed in several excellent reviews $(135,136)$. It has been suggested that liver can accumulate the excess of FFAs as triglycerides, which are the main lipids stored in the liver of patients with NAFLD. In these patients, FFAs accumulation is mainly due to several events, among these, the reduction of fatty acid oxidation, the influx increase, and efflux reduction of fatty acids and, hence, increased de novo lipogenesis (137).

In physiological status, hepatocytes protect themselves by binding, transforming, catabolizing, and exporting excess FFAs.
Although large epidemiological studies suggest triglyceridemediated pathways might negatively affect this disease (138), recent evidence indicates a protective function by triglycerides. In fact, the initial increase in triglyceride synthesis could be considered a beneficial and adaptive response when hepatocytes are exposed to elevated amount of triglyceride metabolites. Therefore, hepatic fat accumulation cannot be considered as a pathology or disease, but rather, as a physiologic response to increased caloric intake (139). However, FFAs and cholesterol, especially when accumulated in mitochondria, are considered the "proactive and aggressive" lipids leading to TNF $\alpha$-mediated liver damage and reactive oxygen species (ROS) formation (140). These lipids could also be present in a non-steatotic liver and act as early "inflammatory" stimuli. Inflammation results in a stress response of hepatocytes, may lead to lipid accumulation, and therefore could precede steatosis and NASH (141); interestingly, patients with NASH may have no or severe steatosis, suggesting that inflammation could take place first.

Lipid accumulation and subsequent lipotoxicity trigger intracellular signaling pathways, which result in pro-inflammatory cytokines that are responsible for cellular recruitment (Figure 1). As above decrypted, hepatic damage is also linked to activation of KCs, HSCs, and sinusoidal endothelial cells, which sustain inflammatory cytokine or mediator secretion. Most of these resident cells are also responsive to inflammatory factors and adipokines secreted by adipocytes. These synergic events can active vicious cycle that amplifies inflammatory process, sustaining steatosis and IR, leading to disease progression and hence worsening hepatic damage $(142,143)$.

The synthesis of cytokines, such as TNF $\alpha$ and IL-6, both involved in inflammatory and metabolic alterations, characterizes the earliest phases of different liver injury, leading to the synthesis of other cytokines that, jointly, induce cell migration and initiate healing processes, including fibrosis (144). A correlation has been found between TNF- $\alpha$ levels and fibrosis degree in NASH patients (145), indeed gene expression of either TNF- $\alpha$ or its receptor is significantly elevated in their hepatic and adipose tissues (146). Similar correlation has been found in NAFLD patients, whose circulating TNF- $\alpha$ are significantly elevated concomitantly with the increase in the activity score, NAS, the histologic scoring system recognized as standard reference in the evaluation and gradation of hepatic inflammation and damage (10). As well, progression of NAFLD correlates with polymorphisms in the TNF- $\alpha$ promoter region and serum level of soluble TNF receptor 2 (147).

Infliximab, a potent TNF- $\alpha$ neutralizing monoclonal antibody used in the treatment of many chronic inflammatory diseases, improves steatosis and insulin signaling both in genetic and nutritional experimental model of IR, reducing inflammation and increasing hormonal sensitivity $(148,149)$. However, using neutralizing anti-TNF antibodies in humans did not show a clear improvement in insulin sensitivity either in rheumatoid arthritis patients (150) or in healthy obese, but insulin resistant, patients (151). Moreover, the treatment with pentoxifylline, a TNF- $\alpha$ inhibitor, reduces amino-transferase serum levels and IR, measured by homeostatic metabolic assessment-insulin resistance (HOMA-IR) in NASH patients $(152,153)$. There is no doubt that 


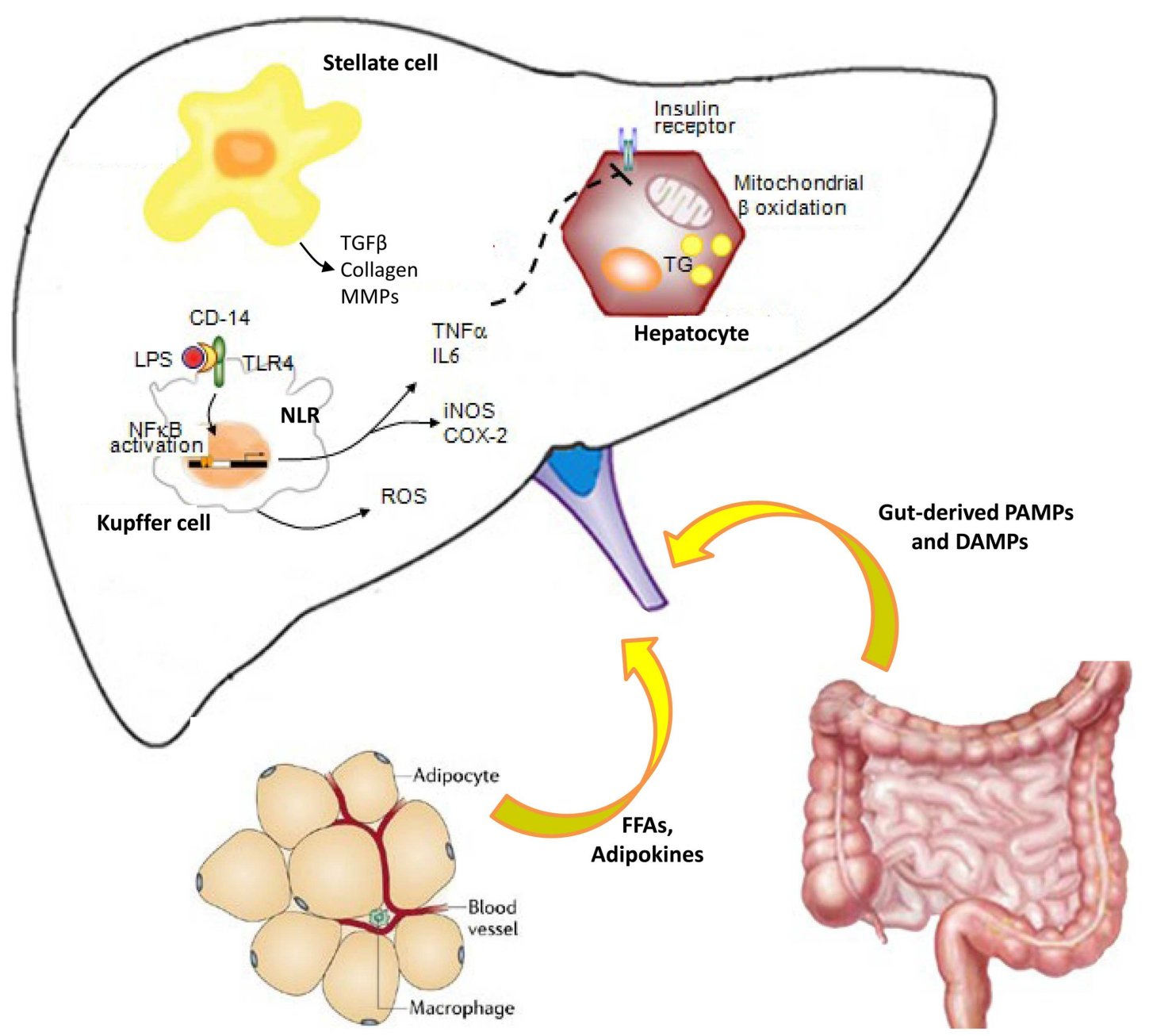

FIGURE 1 | Cross-talk between innate immune cells during liver inflammation: role of adipose tissue and gut. Pathogen-associated molecular patterns (PAMPs) and damage-associated molecular patterns (DAMPs) bind pattern recognition receptors (PRRs), including toll-like receptors (TLRs) and NOD-like receptors (NLRs). Therefore, the liver innate immune cells initiate and sustain hepatic inflammation process, through inflammatory cytokine production. Impairment of intestinal mucosal barrier and/or dysbiosis is responsible for bacterial translocation and elevated endotoxin levels during chronic liver disease, worsening inflammation, and inducing fibrogenesis via Toll-like receptor (TLR) signaling. Kupffer cells are hit by bacterial or insults and contribute to the cytokine production and hepatic stellate cell activation to maintain the balance between inflammatory and fibrogenic signaling. Adipokines secreted from adipose tissue and inflammatory cytokines impaired hepatic insulin signaling, leading to insulin resistance. All these events lead to a vicious cycle that causes worsening of liver damage, further inflammation, and disease progression. low-grade chronic inflammation is part of NAFLD and IR but probably other pro-inflammatory cytokines are of more relevance in metabolic impairment. Thus, TNF- $\alpha$ blockade appears to have no efficacy on IR in humans.

Most cytokine research on obesity-related diseases has centered on IL-6, which was among the first cytokine to be implicated as a predictor or pathogenetic marker of IR and cardiovascular disease. This cytokine plays a key role in the onset of hepatic IR, which was found reduced in obese mice on high fat diet treated with anti-IL-6 antibodies (154). It has been also shown that adipose tissue-derived IL- 6 regulates hepatic IR via up-regulation of SOCS3 (155). Indeed, overexpression of SOCS-3 in the mouse in the mouse liver causes IR and an increase in sterol regulatory element-binding protein (SREBP-1c) that regulates fatty acid synthesis. Conversely, inhibition of SOCS3 in obese diabetic mice improves insulin sensitivity, normalizing the increased SREBP1c expression (124). Recently, increased expression and activity of SREBP pathway, responsible for de novo lipogenesis, has been associated to high fructose exposure in mice. In particular, fructose overconsumption, such as high fat diet, contributes to the development of obesity, dyslipidemia, and impaired glucose tolerance, producing advanced glycation end products (AGEs) responsible for dysfunctional proteins (156). Recently, it has shown that high AGE levels, common in western diet, exacerbate liver injury, inflammation and fibrosis via oxidative stress, cytokine synthesis (TNF $\alpha$ and IL-6), and HSC activation (157). So, AGE and its receptor pathway could be considered a new target for nutritional or pharmacological strategy to slow NAFLD progression. 
IL-6, as well as leptin, activates AMP-activated protein kinase (AMPK) in skeletal muscle and adipose tissue. Leptin is a lipolytic hormone and pro-inflammatory cytokine with important effects in regulating body weight, metabolism, and reproductive function (158-161). Consistent with AMPK activation, IL-6 increases fat oxidation in vitro, ex vivo, and in humans $(162,163)$. A definite answer to the role of IL-6 in IR will be only possible when more clinical data will be available on the use of IL-6-neutralizing antibody in diabetic and/or IR patients. To date only two small clinical trials, however, suggest a beneficial effect. One study assessed the influence of the antibody tocilizumab in rheumatoid arthritis (164). In this study, 10/39 patients were diabetic. This biological therapy resulted in a significant reduction of hemoglobin A1c, suggesting an improvement of hyperglycemia. Similar data have been previously obtained (165). In this small study including on non-diabetic patients, tocilizumab treatment decreased HOMA index significantly and improved insulin sensitivity.

An abnormal leptin secretion may contribute to switch from insulin sensitivity to IR. Hepatic IR and high leptin concentrations are two factors that favor the entry of FFAs into mitochondria and hence the activation of PPAR $\alpha$. Some studies have provided information on the liver disease progression among patients with NASH, for example, those conducted in patients with lipodystrophy, a pathology characterized by reduction of peripheral fat deposition, severe hepatic steatosis, and diabetes, all conditions reversed by leptin administration (166).

Peroxisome proliferator-activated receptor- $\alpha$ is involved in hepatic lipid metabolism, regulating the transcription of genes encoding for enzymes involved in mitochondrial and peroxisomal $\beta$-oxidation. Indeed, PPAR $\alpha$ and peroxisomal $\beta$-oxidation deficiency in mice confirmed the relevance of the alterations in PPAR $\alpha$-inducible $\beta$-oxidation in energy metabolism and in the development of NASH (167).

In NASH, abnormalities in ultrastructure of mitochondria and in peroxidation of plasma/mitochondrial membranes have been described. These modifications induce decreased mitochondrial respiration and impaired ATP generation capacity, leading to mega-mitochondria formation and cell death $(168,169)$. These alterations were correlated with serum TNF $\alpha$, IR, and body weight. Moreover, increased mitochondrial ROS can increase hepatocyte Fas-ligand expression with a consequent activation of apoptotic mechanism of hepatocyte death (170). Lower levels of serum antioxidants are present in patients with NASH. Depletion of antioxidants via lipid peroxidation and free oxygen radical species renders the liver more susceptible to oxidative damage. In fact, treatment with various antioxidants, i.e., glutathione prodrugs ( $S$-adenosylmethionine, betaine, choline), vitamin E, silymarin, decreasing production of ROS reduces steatosis in rats on cholineand methionine-deficient diets or high fat diet $(171,172)$. Also alpha lipoic acid, a naturally occurring thiol antioxidant, showed a hepatoprotective effect, associated with reduced expression of cytochrome P2E1, endoplasmic reticulum stress, and reduction of mitogen-activated protein kinases and NF- $\mathrm{KB}$ activity in mice on choline- and methionine-deficient diet (173). However, several clinical trials of putative antioxidants have been performed in patients with NASH (174-176).
Probiotics, short chain fatty acids, and intervention on gut flora positively prevent liver fat accumulation and inflammation in leptin-deficient mice (149) or rats on high fat diet $(161,177)$. The therapeutic effect of probiotics might be related to a variety of direct and indirect mechanisms, including modification of local microbiota, epithelial barrier function, intestinal inflammation, oxidative stress, or the modulation of immune system (178). Very recently, we studied the effect of butyrate and its synthetic amide derivative on diet-induced NAFLD in rats. The mechanisms of the therapeutic butyrate effect were related to prevention of liver inflammation and damage, steatosis, onset of IR, and imbalance of TLRs pattern in the early stage of NAFLD (177). Butyrate is known to have several distinct mechanisms of action. Among these, the epigenetic mechanism involves the hyperacetylation of histones, by inhibiting class I and class II histone deacetylases and regulating gene transcription and transcription factor activity (179).

In liver, the uncoupling protein (UCP) 2 plays a key role in the adaptive response that preserves the hepatocytes viability in steatotic livers, but it also makes these cells more vulnerable to further insults. Although UCP is barely detectable in hepatocytes from normal adults (180), hepatic synthesis of UCP-2 increases after the induction of PPAR $\alpha$ in these cells (181). The expression and activity of UCP-2 increased in hepatocytes from leptin-deficient mice (182) and from some patients with NASH or alcoholic hepatitis (183). Increased UCP-2 in mitochondria depolarizes the inner mitochondrial membrane, and augments the activity of the electron-transport chain, reducing the superoxide anion formation and calcium accumulation (184). It has been suggested that increased synthesis of UCP-2 in steatotic liver may contribute to inhibition of hepatocyte apoptosis (185), explaining why the activation of PPAR $\alpha$ increases the survival of these cells. It is notable that cells with increased UCP activity show partially depolarized mitochondria and major vulnerability to loss of the mitochondrial inner membrane potential, when exposed to further insults (i.e., TNF $\alpha$ and endotoxin), with consequent depletion of ATP and necrosis (186-188).

The anatomical position of liver between the gut and the systemic circulation and hepatic cellular architecture is clearly responsible for its failure to detoxify endotoxins absorbed from portal circulation after hepatic injury. It might lead to further liver damage and escape of detrimental substances into the general circulation. In advanced stages of NAFLD, as shown in cirrhotic patients, gut-derived products can be involved in the activation of cytokine cascades and subsequent IR (189).

Not only bacterial products from the intestine but also increased translocation of bacteria may impair liver homeostasis and enhance liver inflammation through activation of the innate immune system. Bacterial translocation is defined as the migration of viable bacteria or bacterial products from the intestinal lumen to mesenteric lymph nodes or other extraintestinal organs and sites (190). Recently, it has been demonstrated that during HFD-induced diabetes in mice, commensal intestinal bacteria translocate in pathological manner from intestine toward the tissues where they trigger a local inflammation. This metabolic bacteremia was reversed by a Bifidobacterium animalis strain, which 
reduced the mucosal adherence and bacterial translocation of Gram-negative bacteria from the Enterobacteriaceae group (191).

In particular, translocated bacterial products augment the activation of hepatic immune cells through pattern recognition receptors including TLRs. Recently we demonstrated that, in a rat model of steatosis and IR induced by high fat diet, gut barrier integrity was altered (161). High fat diet induced an up-regulation of transcription and expression of TLR4 and co-receptor CD14 or MyD88 at intestinal and liver level and an imbalance of Gramnegative bacteria (Enterobacteriales and in particular E. coli). Gene expression analysis revealed that in the liver of rats receiving a Lactobacillus paracasei B21060-based synbiotic, TLR 2, 4 and 9, mRNAs expression was restored at physiological level. Therefore, the hepatic inflammatory markers, such as TNF $\alpha$, IL-6, and NF-kB activation, were normalized, along with a restoration of metabolic alterations through normalization of PPAR expression and their target genes. Moreover, the synbiotic improved many aspects of IR, such as fasting response, hormonal homeostasis, glycemic control, and hepatic insulin signaling (161). Consistently with our data, Ehses et al. (192) have reported that TLR2-deficient mice are protected from IR and $\beta$ cell dysfunction induced by HFD, linking TLR2 to the increased dietary lipid and the alteration of glucose homeostasis. Moreover, previous studies showed that the administration of other probiotics (i.e., Lactobacillus and Bifidobacterium) or prebiotics (i.e., inulin and oligofructose) can modulate the microbiota and improve gut permeability, thus controlling the occurrence of endotoxemia (193-197). Additional carefully designed clinical studies based on experimental mechanistic data, are need to provide clinical evidence for the efficacy in NAFLD therapy of probiotics and postbiotics (i.e., short chain fatty acids) alone or in appropriate synergistic combination with standard therapies.

\section{CONCLUSION}

The anatomical position of liver between gut and systemic circulation, the hepatic cellular architecture, and the deep similarity and interconnections between innate immune cells and those resident in liver parenchyma have been highlighted, examining their interplay in the development of liver damage and chronic disease. Both cell types can modulate and interfere with critical processes implicated in metabolic disease and inflammatory pathways, initiating and sustaining liver damage and its progression. Hence, their cross-talk results to play a pivotal role in the development of NAFLD, leading to the various spectrum of NAFLD pathologies.

Further studies are needed to confirm the real beneficial effects of the therapeutic strategies to date available and their possible associations. Moreover, new insights into the different signaling pathways, evoked by innate response and liver inflammation, could provide new insights on NAFLD pathoetiology, identifying new potential therapeutic targets able, above all, to prevent its progression.

\section{REFERENCES}

1. Kubes P, Mehal WZ. Sterile inflammation in the liver. Gastroenterology (2012) 143:1158-72. doi:10.1053/j.gastro.2012.09.008

2. Lumeng CN, Saltiel AR. Inflammatory links between obesity and metabolic disease. J Clin Invest (2011) 121:2111-7. doi:10.1172/JCI57132
3. Seki E, Brenner DA. Toll-like receptors and adaptor molecules in liver disease: update. Hepatology (2008) 48:322-35. doi:10.1002/hep.22306

4. Beutler BA. TLRs and innate immunity. Blood (2009) 113:1399-407. doi:10. 1182/blood-2008-07-019307

5. Beutler B. Neo-ligands for innate immune receptors and the etiology of sterile inflammatory disease. Immunol Rev (2007) 220:113-28. doi:10.1111/j.1600065X.2007.00577.x

6. Bianchi ME. DAMPs, PAMPs and alarmins: all we need to know about danger. J Leukoc Biol (2007) 81:1-5. doi:10.1189/jlb.0306164

7. Lotze MT, Zeh HJ, Rubartelli A, Sparvero LJ, Amoscato AA, Washburn NR, et al. The grateful dead: damage-associated molecular pattern molecules and reduction/oxidation regulate immunity. Immunol Rev (2007) 220:60-81. doi:10.1111/j.1600-065X.2007.00579.x

8. Paz K, Hemi R, LeRoith D, Karasik A, Elhanany E, Kanety H, et al. A molecular basis for insulin resistance. Elevated serine/threonine phosphorylation of IRS-1 and IRS-2 inhibits their binding to the juxtamembrane region of the insulin receptor and impairs their ability to undergo insulin-induced tyrosine phosphorylation. J Biol Chem (1997) 272:29911-8. doi:10.1074/jbc.272. 47.29911

9. Abiru S, Migita K, Maeda Y, Daikoku M, Ito M, Ohata K, et al. Serum cytokine and soluble cytokine receptor levels in patients with non-alcoholic steatohepatitis. Liver Int (2006) 26:39-45. doi:10.1111/j.1478-3231.2005.01191.x

10. Manco M, Marcellini M, Giannone G, Nobili V. Correlation of serum TNF-alpha levels and histologic liver injury scores in pediatric nonalcoholic fatty liver disease. Am J Clin Pathol (2007) 127:954-60. doi:10.1309/ 6VJ4DWGYDU0XYJ8Q

11. Haukeland JW, Damås JK, Konopski Z, Løberg EM, Haaland T, Goverud I, et al. Systemic inflammation in nonalcoholic fatty liver disease is characterized by elevated levels of CCL2. J Hepatol (2006) 44:1167-74. doi:10.1016/j.jhep.2006. 02.011

12. Stienstra R, Joosten LA, Koenen T, van Tits B, van Diepen JA, van den Berg SA, et al. The inflammasome-mediated caspase- 1 activation controls adipocyte differentiation and insulin sensitivity. Cell Metab (2010) 12:593-605. doi:10.1016/j.cmet.2010.11.011

13. Vandanmagsar B, Youm YH, Ravussin A, Galgani JE, Stadler K, Mynatt RL, et al. The NLRP3 inflammasome instigates obesity-induced inflammation and insulin resistance. Nat Med (2011) 17:179-88. doi:10.1038/nm.2279

14. Hotamisligil GS, Erbay E. Nutrient sensing and inflammation in metabolic diseases. Nat Rev Immunol (2008) 8:923-34. doi:10.1038/nri2449

15. Tilg H. The role of cytokines in non-alcoholic fatty liver disease. Dig Dis (2010) 28:179-85. doi:10.1159/000282083

16. Bogdanos DP, Gao B, Gershwin ME. Liver immunology. Compr Physiol (2013) 3:567-98. doi:10.1002/cphy.c120011

17. Kita H, Mackay IR, Van De Water J, Gershwin ME. The lymphoid liver: considerations on pathways to autoimmune injury. Gastroenterology (2001) 120:1485-501. doi:10.1053/gast.2001.22441

18. Lohse AW, Weiler-Normann C, Tiegs G. Immune-mediated liver injury. J Hepatol (2010) 52:136-44. doi:10.1016/j.jhep.2009.10.016

19. Tiegs G, Lohse AW. Immune tolerance: what is unique about the liver. J Autoimmun (2010) 34:1-6. doi:10.1016/j.jaut.2009.08.008

20. Bottcher JP, Knolle PA, Stabenow D. Mechanisms balancing tolerance and immunity in the liver. Dig Dis (2011) 29:384-90. doi:10.1159/000329801

21. Parker GA, Picut CA. Immune functioning in non lymphoid organs: the liver. Toxicol Pathol (2012) 40:237-47. doi:10.1177/0192623311428475

22. Crispe IN. The liver as a lymphoid organ. Annu Rev Immunol (2009) 27:147-63. doi:10.1146/annurev.immunol.021908.132629

23. Pradere JP, Troeger JS, Dapito DH, Mencin AA, Schwabe RF. Toll-like receptor 4 and hepatic fibrogenesis. Semin Liver Dis (2010) 30:232-44. doi:10.1055/s0030- 1255353

24. Tang XZ, Jo J, Tan AT, Sandalova E, Chia A, Tan KC, et al. IL-7 licenses activation of human liver intrasinusoidal mucosal-associated invariant T cells. J Immunol (2013) 190:3142-52. doi:10.4049/jimmunol.1203218

25. Longhi MS, Ma Y, Mieli-Vergani G, Vergani D. Regulatory T cells in autoimmune hepatitis. J Hepatol (2012) 57:932-3. doi:10.1016/j.jhep.2012.05.022

26. Coombes JL, Robey EA. Dynamic imaging of host-pathogen interactions in vivo. Nat Rev Immunol (2010) 10:353-64. doi:10.1038/nri2746

27. Crispe IN. Liver antigen-presenting cells. J Hepatol (2011) 54:357-65. doi:10. 1016/j.jhep.2010.10.005 
28. Thomson AW, Knolle PA. Antigen-presenting cell function in the tolerogenic liver environment. Nat Rev Immunol (2010) 10:753-66. doi:10. $1038 /$ nri2858

29. Lleo A, Invernizzi P. Apotopes and innate immune system: novel players in the primary biliary cirrhosis scenario. Dig Liver Dis (2013) 45:630-6. doi:10.1016/j.dld.2013.01.005

30. Sleyster EC, Knook DL. Relation between localization and function of rat liver Kupffer cells. Lab Invest (1982) 47:484-90.

31. Schulz C, Gomez Perdiguero E, Chorro L, Szabo-Rogers H, Cagnard N, Kierdorf $\mathrm{K}$, et al. A lineage of myeloid cells independent of Myb and hematopoietic stem cells. Science (2012) 336:86-90. doi:10.1126/science.1219179

32. Smedsrod B, De Bleser PJ, Braet F, Lovisetti P, Vanderkerken K, Wisse E, et al. Cell biology of liver endothelial and Kupffer cells. Gut (1994) 35:1509-16. doi:10.1136/gut.35.11.1509

33. Bilzer M, Roggel F, Gerbes AL. Role of Kupffer cells in host defense and liver disease. Liver Int (2006) 26:1175-86. doi:10.1111/j.1478-3231.2006.01342.x

34. Ravetch JV. Fc receptors: rubor redux. Cell (1994) 78:553-60. doi:10.1016/ 0092-8674(94)90521-5

35. Naito M, Hasegawa G, Ebe Y, Yamamoto T. Differentiation and function of Kupffer cells. Med Electron Microsc (2004) 37:16-28. doi:10.1007/s00795-0030228-x

36. Su GL. Lipopolysaccharides in liver injury: molecular mechanisms of Kupffer cell activation. Am J Physiol Gastrointest Liver Physiol (2002) 283:G256-65. doi:10.1152/ajpgi.00550.2001

37. Seki E, Tsutsui H, Tsuji NM, Hayashi N, Adachi K, Nakano H, et al. Critical roles of myeloid differentiation factor 88-dependent proinflammatory cytokine release in early phase clearance of Listeria monocytogenes in mice. J Immunol (2002) 169:3863-8.

38. Knolle P, Schlaak J, Uhrig A, Kempf P, Meyer zum Buschenfelde KH, Gerken G. Human Kupffer cells secrete IL-10 in response to lipopolysaccharide (LPS) challenge. J Hepatol (1995) 22:226-9. doi:10.1016/0168-8278(95)80433-1

39. Seki E, Tsutsui H, Nakano H, Tsuji N, Hoshino K, Adachi O, et al. Lipopolysaccharide-induced IL-18 secretion from murine Kupffer cells independently of myeloid differentiation factor 88 that is critically involved in induction of production of IL-12 and IL-1 $\beta$. J Immunol (2001) 166:2651-7.

40. Kopydlowski KM, Salkowski CA, Cody MJ, van Rooijen N, Major J, Hamilton TA, et al. Regulation of macrophage chemokine expression by lipopolysaccharide in vitro and in vivo. J Immunol (1999) 163:1537-44.

41. Tsutsui H, Matsui K, Okamura H, Nakanishi K. Pathophysiological roles of interleukin-18 in inflammatory liver diseases. Immunol Rev (2000) 174:192-209. doi:10.1034/j.1600-0528.2002.017418.x

42. Sica A, Mantovani A. Macrophage plasticity and polarization: in vivo veritas. J Clin Invest (2012) 122:787-95. doi:10.1172/JCI59643

43. Biswas SK, Mantovani A. Orchestration of metabolism by macrophages. Cell Metab (2012) 15:432-7. doi:10.1016/j.cmet.2011.11.013

44. Bonizzi G, Karin M. The two NF-kappaB activation pathways and their role in innate and adaptive immunity. Trends Immunol (2004) 25:280-8. doi:10.1016/j.it.2004.03.008

45. Lawrence T, Gilroy DW. Chronic inflammation: a failure of resolution? Int J Exp Pathol (2007) 88:85-94. doi:10.1111/j.1365-2613.2006.00507.x

46. Hagemann T, Lawrence T, McNeish I, Charles KA, Kulbe H, Thompson RG, et al. "Re-educating" tumor-associated macrophages by targeting NF-kappaB. J Exp Med (2008) 205:1261-8. doi:10.1084/jem.20080108

47. Gatselis NK, Ntaios G, Makaritsis K, Dalekos GN. Adiponectin: a key playmaker adipocytokine in non-alcoholic fatty liver disease. Clin Exp Med (2013). doi:10.1007/s10238-012-0227-0

48. Takeda N, O’Dea EL, Doedens A, Kim JW, Weidemann A, Stockmann C, et al. Differential activation and antagonistic function of HIF-\{alpha\} isoforms in macrophages are essential for NO homeostasis. Genes Dev (2010) 24:491-501. doi:10.1101/gad.1881410

49. Han MS, Jung DY, Morel C, Lakhani SA, Kim JK, Flavell RA, et al. JNK expression by macrophages promotes obesity-induced insulin resistance and inflammation. Science (2013) 339:218-22. doi:10.1126/science.1227568

50. Liu Y, Chen K, Wang C, Gong W, Yoshimura T, Liu M, et al. Cell surface receptor FPR2 promotes antitumor host defense by limiting $\mathrm{m} 2$ polarization of macrophages. Cancer Res (2013) 73:550-60. doi:10.1158/0008-5472.CAN-122290

51. Liu S, Gallo DJ, Green AM, Williams DL, Gong X, Shapiro RA, et al. Role of toll-like receptors in changes in gene expression and NFkappa B activation in mouse hepatocytes stimulated with lipopolysaccharide. Infect Immun (2002) 70:3433-42. doi:10.1128/IAI.70.7.3433-3442.2002

52. Matsumura T, Degawa T, Takii T, Hayashi H, Okamoto T, Inoue J, et al. TRAF6NF-kappaB pathway is essential for interleukin-1-induced TLR2 expression and its functional response to TLR2 ligand in murine hepatocytes. Immunology (2003) 109:127-36. doi:10.1046/j.1365-2567.2003.01627.x

53. Mimura Y, Sakisaka S, Harada M, Sata M, Tanikawa K. Role of hepatocytes in direct clearance of lipopolysaccharide in rats. Gastroenterology (1995) 109:1969-76. doi:10.1016/0016-5085(95)90765-3

54. Scott MJ, Billiar TR. Beta2-integrin-induced p38 MAPK activation is a key mediator in the CD14/TLR4/MD2-dependent uptake of lipopolysaccharide by hepatocytes. J Biol Chem (2008) 283:29433-46. doi:10.1074/jbc.M803905200

55. Friedman SL. Hepatic stellate cells: protean, multifunctional, and enigmatic cells of the liver. Physiol Rev (2008) 88:125-72. doi:10.1152/physrev.00013.2007

56. Blaner WS, O’Byrne SM, Wongsiriroj N, Kluwe J, D’Ambrosio DM, Jiang H, et al. Hepatic stellate cell lipid droplets: a specialized lipid droplet for retinoid storage. Biochim Biophys Acta (2009) 1791:467-73. doi:10.1016/j.bbalip.2008. 11.001

57. Carotti S, Morini S, Corradini SG, Burza MA, Molinaro A, Carpino G, et al. Glial fibrillary acidic protein as an early marker of hepatic stellate cell activation in chronic and posttransplant recurrent hepatitis C. Liver Transpl (2008) 14:806-14. doi:10.1002/lt.21436

58. Carpino G, Franchitto A, Morini S, Corradini SG, Merli M, Gaudio E. Activated hepatic stellate cells in liver cirrhosis. A morphologic and morphometrical study. Ital J Anat Embryol (2004) 109:225-38.

59. Carpino G, Morini S, Ginanni Corradini S, Franchitto A, Merli M, Siciliano $\mathrm{M}$, et al. Alpha-SMA expression in hepatic stellate cells and quantitative analysis of hepatic fibrosis in cirrhosis and in recurrent chronic hepatitis after liver transplantation. Dig Liver Dis (2005) 37:349-56. doi:10.1016/j.dld.2004.11.009

60. Fujii H, Kawada N. Inflammation and fibrogenesis in steatohepatitis. J Gastroenterol (2012) 47:215-25. doi:10.1007/s00535-012-0527- $\mathrm{x}$

61. Tsukamoto H, She H, Hazra S, Cheng J, Miyahara T. Anti-adipogenic regulation underlies hepatic stellate cell transdifferentiation. J Gastroenterol Hepatol (2006) 21:S102-5. doi:10.1111/j.1440-1746.2006.04573.x

62. Tsukamoto H, Zhu NL, Asahina K, Mann DA, Mann J. Epigenetic cell fate regulation of hepatic stellate cells. Hepatol Res (2011) 41:675-82. doi:10.1111/j. 1872-034X.2011.00804.x

63. Choi SS, Witek RP, Yang L, Omenetti A, Syn WK, Moylan CA, et al. Activation of Racl promotes hedgehog-mediated acquisition of the myofibroblastic phenotype in rat and human hepatic stellate cells. Hepatology (2010) 52:278-90. doi:10.1002/hep.23649

64. De Minicis S, Svegliati-Baroni G. Fibrogenesis in nonalcoholic steatohepatitis. Expert Rev Gastroenterol Hepatol (2011) 5:179-87. doi:10.1586/egh.11.28

65. Choi SS, Syn WK, Karaca GF, Omenetti A, Moylan CA, Witek RP, et al. Leptin promotes the myofibroblastic phenotype in hepatic stellate cells by activating the hedgehog pathway. J Biol Chem (2010) 285:36551-60. doi:10.1074/jbc. M110.168542

66. Marra F, Aleffi S, Bertolani C, Petrai I, Vizzutti F. Adipokines and liver fibrosis. Eur Rev Med Pharmacol Sci (2005) 9:279-84.

67. Ikejima K, Takei Y, Honda H, Hirose M, Yoshikawa M, Zhang YJ, et al. Leptin receptor-mediated signaling regulates hepatic fibrogenesis and remodeling of extracellular matrix in the rat. Gastroenterology (2002) 122:1399-410. doi:10.1053/gast.2002.32995

68. Bataller R, Sancho-Bru P, Ginés P, Lora JM, Al-Garawi A, Solè M, et al. Activated human hepatic stellate cells express the renin-angiotensin system and synthesize angiotensin II. Gastroenterology (2003) 125:117-25. doi:10.1016/S00165085(03)00695-4

69. Bataller R, Ginès P, Nicolás JM, Görbig MN, Garcia-Ramallo E, Gasull X, et al. Angiotensin II induces contraction and proliferation of human hepatic stellate cells. Gastroenterology (2000) 118:1149-56. doi:10.1016/S0016-5085(00) 70368-4

70. Bataller R, Schwabe RF, Choi YH, Yang L, Paik YH, Lindquist J, et al. NADPH oxidase signal transduces angiotensin II in hepatic stellate cells and is critical in hepatic fibrosis. J Clin Invest (2003) 112:1383-94. doi:10.1172/JCI18212

71. Seki E, De Minicis S, Osterreicher CH, Kluwe J, Osawa Y, Brenner DA, et al. TLR4 enhances TGF-beta signaling and hepatic fibrosis. Nat Med (2007) 13:1324-32. doi:10.1038/nm1663

72. Kaji K, Yoshiji H, Kitade M, Ikenaka Y, Noguchi R, Shirai Y, et al. Combination treatment of angiotensin II type I receptor blocker and new oral iron chelator 
attenuates progression of nonalcoholic steatohepatitis in rats. Am J Physiol Gastrointest Liver Physiol (2011) 300:G1094-104. doi:10.1152/ajpgi.00365.2010

73. Chiba M, Sasaki M, Kitamura S, Ikeda H, Sato Y, Nakanuma Y. Participation of bile ductular cells in the pathological progression of non-alcoholic fatty liver disease. J Clin Pathol (2011) 64:564-70. doi:10.1136/jcp.2011.090175

74. Harada K, Ohira S, Isse K, Ozaki S, Zen Y, Sato Y, et al. Lipopolysaccharide activates nuclear factor- $\mathrm{kB}$ through toll-like receptors and related molecules in cultured biliary epithelial cells. Lab Invest (2003) 83:1657-67. doi:10.1097/01.LAB.0000097190.56734.FE

75. Ikeda H, Sasaki M, Ishikawa A, Sato Y, Harada K, Zen Y, et al. Interaction of Toll-like receptors with bacterial components induces expression of CDX2 and MUC2 in rat biliary epithelium in vivo and in culture. Lab Invest (2007) 87:559-71. doi:10.1038/labinvest.3700556

76. Chen XM, O'Hara SP, Nelson JB, Splinter PL, Small AJ, Tietz PS, et al. Multiple TLRs are expressed in human cholangiocytes and mediate host epithelial defense responses to Cryptosporidium parvum via activation of NF-kappaB. J Immunol (2005) 175:7447-56.

77. Harada K, Isse K, Nakanuma Y. Interferon gamma accelerates NF-kappaB activation of biliary epithelial cells induced by Toll-like receptor and ligand interaction. J Clin Pathol (2006) 59:184-90. doi:10.1136/jcp.2004.023507

78. De Creus A, Abe M, Lau AH, Hackstein H, Raimondi G, Thomson AW. Low TLR4 expression by liver dendritic cells correlates with reduced capacity to activate allogeneic T cells in response to endotoxin. J Immunol (2005) 174:2037-45.

79. Shu SA, Lian ZX, Chuang YH, Yang GX, Moritoki Y, Comstock SS, et al. The role of $\mathrm{CD} 11 \mathrm{c}(+)$ hepatic dendritic cells in the induction of innate immune responses. Clin Exp Immunol (2007) 149:335-43. doi:10.1111/j.1365-2249. 2007.03419.x

80. Uhrig A, Banafsche R, Kremer M, Hegenbarth S, Hamann A, Neurath M, et al. Development and functional consequences of LPS tolerance in sinusoidal endothelial cells of the liver. J Leukoc Biol (2005) 77:626-33. doi:10.1189/jlb. 0604332

81. Wu J, Lu M, Meng Z, Jiang M, Pei R, Trippler M, et al. Toll-like receptormediated control of HBV replication by nonparenchymal liver cells in mice. Hepatology (2007) 46:1769-78. doi:10.1002/hep. 21897

82. Van Bossuyt H, De Zanger RB, Wisse E. Cellular and subcellular distribution of injected lipopolysaccharide in rat liver and its inactivation by bile salts. J Hepatol (1988) 7:325-37. doi:10.1016/S0168-8278(88)80005-9

83. Takeuchi O, Akira S. Pattern recognition receptors and inflammation. Cell (2010) 140:805-20. doi:10.1016/j.cell.2010.01.022

84. Yamamoto M, Takeda K. Current views of toll-like receptor signaling pathways. Gastroenterol Res Pract (2010) 2010:240365. doi:10.1155/2010/240365

85. Kumar H, Kawai T, Akira S. Pathogen recognition by the innate immune system. Int Rev Immunol (2011) 30:1-34. doi:10.3109/08830185.2010.529976

86. Casanova JL, Abel L, Quintana-Murci L. Human TLRs and IL-1Rs in host defense: natural insights from evolutionary, epidemiological and clinical genetics. Annu Rev Immunol (2011) 29:447-91. doi:10.1146/annurev-immunol030409-101335

87. Khoo JJ, Forster S, Mansell A. Toll-like receptors as interferon-regulated genes and their role in disease. J Interferon Cytokine Res (2011) 31:13-25. doi:10.1089/jir.2010.0095

88. Ekihiro S, Brenner DA. Toll-like receptors and adaptor molecules in liver disease: updates. Hepatology (2008) 48:322-35. doi:10.1002/hep.22306

89. Aoyama T, Paik YH, Seki E. Toll-like receptor signalling and liver fibrosis. Gastroenterol Res Pract (2010) 2010:192543. doi:10.1155/2010/192543

90. Iimuro Y, Fujimoto J. TLRs, NF-kB, JNK, and liver regeneration. Gastroenterol Res Pract (2010) 2010:598109. doi:10.1155/2010/598109

91. McGettrick AF, O'Neill LA. Localisation and trafficking of Toll-like receptors: an important mode of regulation. Curr Opin Immunol (2010) 22:20-7. doi:10.1016/j.coi.2009.12.002

92. Broering R, Lu M, Schlaak JF. Role of Toll-like receptors in liver health and disease. Clin Sci (Lond) (2011) 121:415-26. doi:10.1042/CS20110065

93. Miura K, Kodama Y, Inokuchi S, Schnabl B, Aoyama T, Ohnishi H, et al. Tolllike receptor 9 promotes steatohepatitis by induction of interleukin-1beta in mice. Gastroenterology (2010) 139:323-34. doi:10.1053/j.gastro.2010.03.052

94. Rivera CA, Gaskin L, Allman M, Pang J, Brady K, Adegboyega P, et al. Toll-like receptor-2 deficiency enhances non-alcoholic steatohepatitis. BMC Gastroenterol (2010) 10:52. doi:10.1186/1471-230X-10-52

95. Csak T, Velayudham A, Hritz I, Petrasek J, Levin I, Lippai D, et al. Deficiency in myeloid differentiation factor- 2 and toll-like receptor 4 expression attenuates nonalcoholic steatohepatitis and fibrosis in mice. Am J Physiol Gastrointest Liver Physiol (2011) 300:433-41. doi:10.1152/ajpgi.00163.2009

96. Spruss A, Kanuri G, Wagnerberger S, Haub S, Bischoff SC, Bergheim I. Toll-like receptor 4 is involved in the development of fructose-induced hepatic steatosis in mice. Hepatology (2009) 50:1094-104. doi:10.1002/hep.23122

97. Bamboat ZM, Balachandran VP, Ocuin LM, Obaid H, Plitas G, DeMatteo RP. Toll-like receptor 9 inhibition confers protection from liver ischemia-reperfusion injury. Hepatology (2010) 51:621-32. doi:10.1002/hep. 23365

98. Imaeda AB, Watanabe A, Sohail MA, Mahmood S, Mohamadnejad M, Sutterwala FS, et al. Acetaminophen-induced hepatotoxicity in mice is dependent on Tlr9 and the Nalp3 inflammasome. J Clin Invest (2009) 119:305-14. doi:10.1172/JCI35958

99. Seki E, Schnabl B. Role of innate immunity and the microbiota in liver fibrosis-crosstalk between the liver and gut. J Physiol (2012) 590:447-58. doi:10.1113/jphysiol.2011.219691

100. Caricilli AM, Picardi PK, de Abreu LL, Ueno M, Prada PO, Ropelle ER, et al. Gut microbiota is a key modulator of insulin resistance in TLR2 knockout mice. PLoS Biol (2011) 9:e1001212. doi:10.1371/journal.pbio.1001212

101. Saitoh T, Akira S. Regulation of innate immune responses by autophagy-related proteins. J Cell Biol (2010) 189:925-35. doi:10.1083/jcb.201002021

102. Saitoh T, Fujita N, Jang MH, Uematsu S, Yang BG, Satoh T, et al. Loss of the autophagy protein Atg16L1 enhances endotoxin-induced IL-1beta production. Nature (2008) 456:264-8. doi:10.1038/nature07383

103. Ravikumar B, Sarkar S, Davies JE, Futter M, Garcia-Arencibia M, GreenThompson ZW, et al. Regulation of mammalian autophagy in physiology and pathophysiology. Physiol Rev (2010) 90:1383-435. doi:10.1152/physrev.00030. 2009

104. Fukada H, Yamashina S, Izumi K, Komatsu M, Tanaka K, Ikejima K, et al. Suppression of autophagy sensitizes Kupffer cells to endotoxin. Hepatol Res (2012) 42:1112-8. doi:10.1111/j.1872-034X.2012.01024.x

105. Martinon F, Mayor A, Tschopp J. The inflammasomes: guardians of the body. Annu Rev Immunol (2009) 27:229-65. doi:10.1146/annurev.immunol.021908. 132715

106. Pedra JH, Cassel SL, Sutterwala FS. Sensing pathogens and danger signals by the inflammasome. Curr Opin Immunol (2009) 21:10-6. doi:10.1016/j.coi.2009. 01.006

107. Clarke TB, Davis KM, Lysenko ES, Zhou AY, Yu Y, Weiser JN. Recognition of peptidoglycan from the microbiota by Nod1 enhances systemic innate immunity. Nat Med (2010) 16:228-31. doi:10.1038/nm.2087

108. Kersse K, Bertrand MJ, Lamkanfi M, Vandenabeele P. NOD-like receptors and the innate immune system: coping with danger, damage and death. Cytokine Growth Factor Rev (2011) 22:257-76. doi:10.1016/j.cytogfr.2011.09.003

109. Sutterwala FS, Ogura Y, Flavell RA. The inflammasome in pathogen recognition and inflammation. J Leukoc Biol (2007) 82:259-64. doi:10.1189/jlb.1206755

110. Strowig T, Henao-Mejia J, Elinav E, Flavell R. Inflammasomes in health and disease. Nature (2012) 481:278-86. doi:10.1038/nature10759

111. Dinarello CA. Immunological and inflammatory functions of the interleukin-1 family. Annu Rev Immunol (2009) 27:519-50. doi:10.1146/annurev.immunol. 021908.132612

112. Csak T, Ganz M, Pespisa J, Kodys K, Dolganiuc A, Szabo G. Fatty acid and endotoxin activate inflammasomes in mouse hepatocytes that release danger signals to stimulate immune cells. Hepatology (2011) 54:133-44. doi:10.1002/hep.24341

113. Dixon LJ, Flask CA, Papouchado BG, Feldstein AE, Nagy LE. Caspase-1 as a central regulator of high fat diet-induced non-alcoholic steatohepatitis. PLoS One (2013) 8:e56100. doi:10.1371/journal.pone.0056100

114. Wen H, Gris D, Lei Y, Jha S, Zhang L, Huang MT, et al. Fatty acid-induced NLRP3-ASC inflammasome activation interferes with insulin signaling. Nat Immunol (2011) 12:408-15. doi:10.1038/ni.2022

115. Stienstra R, van Diepen JA, Tack CJ, Zaki MH, van de Veerdonk FL, Perera D, et al. Inflammasome is a central player in the induction of obesity and insulin resistance. Proc Natl Acad Sci U S A (2011) 108:15324-9. doi:10.1073/pnas. 1100255108

116. Petrasek J, Bala S, Csak T, Lippai D, Kodys K, Menashy V, et al. IL-1 receptor antagonist ameliorates inflammasome-dependent alcoholic steatohepatitis in mice. J Clin Invest (2012) 122:3476-89. doi:10.1172/JCI60777

117. Szabo G, Csak T. Inflammasomes in liver diseases. J Hepatol (2012) 57:642-54. doi:10.1016/j.jhep.2012.03.035 
118. Zhu P, Duan L, Chen J, Xiong A, Xu Q, Zhang H, et al. Gene silencing of NALP3 protects against liver ischemia-reperfusion injury in mice. Hum Gene Ther (2011) 22:853-64. doi:10.1089/hum.2010.145

119. Bauernfeind FG, Horvath G, Stutz A, Alnemri ES, MacDonald K, Speert D, et al. Cutting edge: NF-kappaB activating pattern recognition and cytokine receptors license NLRP3 inflammasome activation by regulating NLRP3 expression. J Immunol (2009) 183:787-91. doi:10.4049/jimmunol.0901363

120. Ganz M, Csak T, Nath B, Szabo G. Lipopolysaccharide induces and activates the Nalp3 inflammasome in the liver. World J Gastroenterol (2011) 17:4772-8. doi:10.3748/wjg.v17.i43.4772

121. Sondergaard L. Homology between the mammalian liver and Drosophila fat body. Trends Genet (1993) 9:193. doi:10.1016/0168-9525(93)90113-V

122. Beutler B. Innate immunity: an overview. Mol Immunol (2004) 40:845-59. doi:10.1016/j.molimm.2003.10.005

123. Shi H, Kokoeva MV, Inouye K, Tzameli I, Yin H, Flier JS. TLR4 links innate immunity and fatty acid-induced insulin resistance. J Clin Invest (2006) 116:3015-25. doi:10.1172/JCI28898

124. Hotamisligil GS. Inflammation and metabolic disorders. Nature (2006) 444:860-7. doi:10.1038/nature05485

125. Karalis KP, Giannogonas P, Kodela E, Koutmani Y, Zoumakis M, Teli T. Mechanisms of obesity and related pathology: linking immune responses to metabolic stress. FEBS J (2009) 276:5747-54. doi:10.1111/j.1742-4658.2009.07304.x

126. Gastaldelli A, Miyazaki Y, Pettiti M, Santini E, Ciociaro D, Defronzo RA, et al. The effect of rosiglitazone on the liver: decreased gluconeogenesis in patients with type 2 diabetes. J Clin Endocrinol Metab (2006) 91:806-12. doi:10.1210/jc.2005-1159

127. Bugianesi E, Gastaldelli A, Vanni E, Gambino R, Cassader M, Baldi S, et al. Insulin resistance in non-diabetic patients with non-alcoholic fatty liver disease: sites and mechanisms. Diabetologia (2005) 48:634-42. doi:10.1007/ s00125-005-1682-x

128. Seppala-Lindroos A, Vehkavaara S, Häkkinen AM, Goto T, Westerbacka J, Sovijärvi A, et al. Fat accumulation in the liver is associated with defects in insulin suppression of glucose production and serum free fatty acids independent of obesity in normal men. J Clin Endocrinol Metab (2002) 87:3023-8. doi:10.1210/jcem.87.7.8638

129. Gastaldelli A, Cusi K, Pettiti M, Hardies J, Miyazaki Y, Berria R, et al. Relationship between hepatic/visceral fat and hepatic insulin resistance in nondiabetic and type 2 diabetic subjects. Gastroenterology (2007) 133:496-506. doi:10.1053/j.gastro.2007.04.068

130. Stein LL, Dong MH, Loomba R. Insulin sensitizers in nonalcoholic fatty liver disease and steatohepatitis: current status. Adv Ther (2009) 26:893-907. doi:10.1007/s12325-009-0072-z

131. Nobili V, Manco M, Ciampalini P, Alisi A, Devito R, Bugianesi E, et al. Metformin use in children with nonalcoholic fatty liver disease: an open label, 24-month, observational pilot study. Clin Ther (2008) 30:1168-76. doi:10.1016/j.clinthera.2008.06.012

132. Mohanty P, Aljada A, Ghanim H, Hofmeyer D, Tripathy D, Syed T, et al. Evidence for a potent antiinflammatory effect of rosiglitazone. J Clin Endocrinol Metab (2004) 89:2728-35. doi:10.1210/jc.2003-032103

133. Lutchman G, Modi A, Kleiner DE, Promrat K, Heller T, Ghany M, et al. The effects of discontinuing pioglitazone in patients with non-alcoholic steatohepatitis. Hepatology (2007) 46:424-9. doi:10.1002/hep.21661

134. Nseir W, Mograbi J, Ghali M. Lipid-lowering agents in nonalcoholic fatty liver disease and steatohepatitis: human studies. Dig Dis Sci (2012) 57:1773-81. doi:10.1007/s10620-012-2118-3

135. Malhi H, Gores GJ. Molecular mechanisms of lipotoxicity in nonalcoholic fatty liver disease. Semin Liver Dis (2008) 28:360-9. doi:10.1055/s-0028- 1091980

136. Alkhouri N, Dixon LJ, Feldstein AE. Lipotoxicity in nonalcoholic fatty liver disease: not all lipids are created equal. Expert Rev Gastroenterol Hepatol (2009) 3:445-51. doi:10.1586/egh.09.32

137. Parekh S, Anania FA. Abnormal lipid and glucose metabolism in obesity: implications for nonalcoholic fatty liver disease. Gastroenterology (2007) 132:2191-207. doi:10.1053/j.gastro.2007.03.055

138. Sarwar N, Sandhu MS, Ricketts SL, Butterworth AS, Di Angelantonio E, Boekholdt SM, et al. Triglyceride-mediated pathways and coronary disease: collaborative analysis of 101 studies. Lancet (2010) 375:1634-9. doi:10.1016/ S0140-6736(10)60545-4
139. Tilg H, Moschen AR. Evolution of inflammation in nonalcoholic fatty liver disease: the multiple parallel hits hypothesis. Hepatology (2010) 52:1836-46. doi:10.1002/hep. 24001

140. Feldstein AE, Werneburg NW, Canbay A, Guicciardi ME, Bronk SF, Rydzewski $\mathrm{R}$, et al. Free fatty acids promote hepatic lipotoxicity by stimulating TNFalpha expression via a lysosomal pathway. Hepatology (2004) 40:185-94. doi:10.1002/hep.20283

141. Tiniakos DG, Vos MB, Brunt EM. Nonalcoholic fatty liver disease: pathology and pathogenesis. Annu Rev Pathol (2010) 5:145-71. doi:10.1146/annurevpathol-121808-102132

142. Marra F, Gastaldelli A, Svegliati Baroni G, Tell G, Tiribelli C. Molecular basis and mechanisms of progression of non-alcoholic steatohepatitis. Trends $\mathrm{Mol}$ Med (2008) 14:72-81. doi:10.1016/j.molmed.2007.12.003

143. Bieghs V, Trautwein C. The innate immune response during liver inflammation and metabolic disease. Trends Immunol (2013) 34:446-52. doi:10.1016/j. it.2013.04.005

144. Tilg H, Diehl AM. Cytokines in alcoholic and nonalcoholic steatohepatitis. N Engl J Med (2000) 343:1467-76. doi:10.1056/NEJM200011163432007

145. Jarrar MH, Baranova A, Collantes R, Ranard B, Stepanova M, Bennett C, et al. Adipokines and cytokines in non-alcoholic fatty liver disease. Aliment Pharmacol Ther (2008) 27:412-21. doi:10.1111/j.1365-2036.2007.03586.x

146. Crespo J, Cayon A, Fernandez-Gil P, Hernandez-Guerra M, Mayorga M, Dominguez-Diez A, et al. Gene expression of tumor necrosis factor alpha and TNF-receptors, p55 and p75, in nonalcoholic steatohepatitis patients. Hepatology (2001) 34:1158-63. doi:10.1053/jhep.2001.29628

147. Tokushige K, Takakura M, Tsuchiya-Matsushita N, Taniai M, Hashimoto E, Shiratori K. Influence of TNF gene polymorphisms in Japanese patients with NASH and simple steatosis. J Hepatol (2007) 46:1104-10. doi:10.1016/j.jhep. 2007.01.028

148. Barbuio R, Milanski M, Bertolo MB, Saad MJ, Velloso LA. Infliximab reverses steatosis and improves insulin signal transduction in liver of rats fed a high-fat diet. J Endocrinol (2007) 194:539-50. doi:10.1677/JOE-07-0234

149. Li Z, Yang S, Lin H, Huang J, Watkins PA, Moser AB, et al. Probiotics and antibodies to TNF inhibit inflammatory activity and improve nonalcoholic fatty liver disease. Hepatology (2003) 37:343-50. doi:10.1053/jhep.2003.50048

150. Ferraz-Amaro I, Arce-Franco M, Muniz J, López-Fernández J, HernándezHernández V, Franco A, et al. Systemic blockade of TNF- $\alpha$ does not improve insulin resistance in humans. Horm Metab Res (2011) 43:801-8. doi:10.1055/ s-0031-1287783

151. Wascher TC, Lindeman JH, Sourij H, Kooistra T, Pacini G, Roden M. Chronic TNF- $\alpha$ neutralization does not improve insulin resistance or endothelial function in "healthy" men with metabolic syndrome. Mol Med (2011) 17:189-93. doi:10.2119/molmed.2010.00221

152. Adams LA, Zein CO, Angulo P, Lindor KD. A pilot trial of pentoxifylline in nonalcoholic steatohepatitis. Am J Gastroenterol (2004) 99:2365-8. doi:10.1111/j. 1572-0241.2004.40064.x

153. Satapathy SK, Garg S, Chauhan R, Sakhuja P, Malhotra V, Sharma BC, et al. Beneficial effects of tumor necrosis factor-alpha inhibition by pentoxifylline on clinical, biochemical, and metabolic parameters of patients with nonalcoholic steatohepatitis. Am J Gastroenterol (2004) 99:1946-52. doi:10.1111/j. 1572-0241.2004.40220.x

154. Klover PJ, Clementi AH, Mooney RA. Interleukin-6 depletion selectively improves hepatic insulin action in obesity. Endocrinology (2005) 146:3417-27. doi:10.1210/en.2004-1468

155. Sabio G, Das M, Mora A, Zhang Z, Jun JY, Barrett T, et al. A stress signaling pathway in adipose tissue regulates hepatic insulin resistance. Science (2008) 322:1539-43. doi:10.1126/science.1160794

156. Mastrocola R, Collino M, Rogazzo M, Medana C, Nigro D, Boccuzzi G, et al. Advanced glycation end products promote hepatosteatosis by interfering with SCAP-SREBP pathway in fructose-drinking mice. Am J Physiol Gastrointest Liver Physiol (2013) 305:G398-407. doi:10.1152/ajpgi.00450.2012

157. Leung C, Herath CB, Jia Z, Goodwin M, Mak KY, Watt MJ, et al. Dietary glycotoxins exacerbate progression of experimental fatty liver disease. J Hepatol (2014) 60:832-8. doi:10.1016/j.jhep.2013.11.033

158. Conde J, Scotece M, Gómez R, Gómez-Reino JJ, Lago F, Gualillo O. At the crossroad between immunity and metabolism: focus on leptin. Expert Rev Clin Immunol (2010) 6:801-8. doi:10.1586/eci.10.48 
159. Meli R, Pacilio M, Mattace Raso G, Esposito E, Coppola A, Nasti A, et al. Estrogen and raloxifene modulate leptin and its receptor in hypothalamus and adipose tissue from ovariectomized rats. Endocrinology (2004) 145:3115-21. doi:10.1210/en.2004-0129

160. Mattace Raso G, Bianco G, Iacono A, Esposito E, Autore G, Ferrante MC, et al. Maternal adaptations to pregnancy in spontaneously hypertensive rats: leptin and ghrelin evaluation. J Endocrinol (2007) 194:611-9. doi:10.1677/JOE-070159

161. Mattace Raso G, Santoro A, Russo R, Simeoli R, Paciello O, Di Carlo C, et al. Palmitoylethanolamide prevents metabolic alterations and restores leptin sensitivity in ovariectomized rats. Endocrinology (2014) 155:1291-301. doi:10.1210/en.2013-1823

162. Yuen DY, Dwyer RM, Matthews VB, Zhang L, Drew BG, Neill B, et al. Interleukin-6 attenuates insulin-mediated increases in endothelial cell signaling but augments skeletal muscle insulin action via differential effects on tumor necrosis factor-alpha expression. Diabetes (2009) 58:1086-95. doi:10.2337/db08-0775

163. Wieser V, Moschen AR, Tilg H. Inflammation, cytokines and insulin resistance: a clinical perspective. Arch Immunol Ther Exp (Warsz) (2013) 61:119-25. doi:10.1007/s00005-012-0210-1

164. Ogata A, Morishima A, Hirano T, Hishitani Y, Hagihara K, Shima Y, et al. Improvement of $\mathrm{HbAlc}$ during treatment with humanised anti-interleukin 6 receptor antibody, tocilizumab. Ann Rheum Dis (2011) 70:1164-5. doi:10. 1136/ard.2010.132845

165. Schultz O, Oberhauser F, Saech J, Rubbert-Roth A, Hahn M, Krone W, et al. Effects of inhibition of interleukin-6 signaling on insulin sensitivity and lipoprotein (a) levels in human subjects with rheumatoid diseases. PLoS One (2010) 5:e14328. doi:10.1371/journal.pone.0014328

166. Barzilai N, Wang J, Massilon D, Vuguin P, Hawkins M, Rossetti L. Leptin selectively decreases visceral adiposity and enhances insulin action. J Clin Invest (1997) 100:3105-10. doi:10.1172/JCI119865

167. Reddy JK. Nonalcoholic steatosis and steatohepatitis. III. Peroxisomal betaoxidation, PPAR alpha, and steatohepatitis. Am J Physiol Gastrointest Liver Physiol (2001) 281:G1333-9.

168. Pessayre D, Berson A, Fromenty B, Mansouri A. Mitochondria in steatohepatitis. Semin Liver Dis (2001) 21:57-69. doi:10.1055/s-2001- 12929

169. Pérez-Carreras M, Del Hoyo P, Martín MA, Rubio JC, Martín A, Castellano G, et al. Defective hepatic mitochondrial respiratory chain in patients with nonalcoholic steatohepatitis. Hepatology (2003) 38:999-1007. doi:10.1053/jhep. 2003.50398

170. Feldstein AE, Canbay A, Angulo P, Taniai M, Burgart LJ, Lindor KD, et al. Hepatocyte apoptosis and fas expression are prominent features of human nonalcoholic steatohepatitis. Gastroenterology (2003) 125:437-43. doi:10.1016/S00165085(03)00907-7

171. Vendemiale G, Altomare E, Trizio T, Le Grazie C, Di Padova C, Salerno MT, et al. Effects of oral S-adenosyl-L-methionine on hepatic glutathione in patients with liver disease. Scand J Gastroenterol (1989) 24:407-15. doi:10. 3109/00365528909093067

172. Mattace Raso G, Esposito E, Iacono A, Pacilio M, Cuzzocrea S, Berni Canani $\mathrm{R}$, et al. Comparative therapeutic effects of metformin and vitamin $\mathrm{E}$ in a model of non-alcoholic steatohepatitis in the young rat. Eur J Pharmacol (2009) 604:125-31. doi:10.1016/j.ejphar.2008.12.013

173. Min AK, Kim MK, Kim HS, Seo HY, Lee KU, Kim JG, et al. Alpha-lipoic acid attenuates methionine choline deficient diet-induced steatohepatitis in C57BL/6 mice. Life Sci (2012) 90:200-5. doi:10.1016/j.lfs.2011.11.012

174. Vajro P, Mandato C, Franzese A, Ciccimarra E, Lucariello S, Savoia M, et al. Vitamin E treatment in pediatric obesity-related liver disease: a randomized study. J Pediatr Gastroenterol Nutr (2004) 38:48-55. doi:10.1097/00005176200401000-00012

175. Pacana T, Sanyal AJ. Vitamin E and nonalcoholic fatty liver disease. Curr Opin Clin Nutr Metab Care (2012) 15:641-8. doi:10.1097/MCO.0b013e328357f747

176. Hoofnagle JH, Van Natta ML, Kleiner DE, Clark JM, Kowdley KV, Loomba R, et al. Non-alcoholic Steatohepatitis Clinical Research Network (NASH CRN). Vitamin $\mathrm{E}$ and changes in serum alanine aminotransferase levels in patients with non-alcoholic steatohepatitis. Aliment Pharmacol Ther (2013) 38:134-43. doi:10.1111/apt.12352

177. Mattace Raso G, Simeoli R, Russo R, Iacono A, Santoro A, Paciello O, et al. Effects of sodium butyrate and its synthetic amide derivative on liver inflammation and glucose tolerance in an animal model of steatosis induced by high fat diet. PLoS One (2013) 8:e68626. doi:10.1371/journal.pone. 0068626

178. Iacono A, Mattace Raso G, Berni Canani R, Calignano A, Meli R. Probiotics as an emerging therapeutic strategy to treat NAFLD: focus on molecular and biochemical mechanisms. J Nutr Biochem (2011) 22:699-711. doi:10.1016/j.jnutbio.2010.10.002

179. Berni Canani R, Di Costanzo M, Leone L, Pedata M, Meli R, Calignano A. Potential beneficial effects of butyrate in intestinal and extraintestinal diseases. World J Gastroenterol (2011) 17:1519-28. doi:10.3748/wjg.v17.i12.1519

180. Fleury C, Neverova M, Collins S, Raimbault S, Champigny O, Levi-Meyrueis C, et al. Uncoupling protein-2: a novel gene linked to obesity and hyperinsulinemia. Nat Genet (1997) 15:269-72. doi:10.1038/ng0397-269

181. Kelly LJ, Vicario PP, Thompson GM, Candelore MR, Doebber TW, Ventre J, et al. Peroxisome proliferator-activated receptors gamma and alpha mediate in vivo regulation of uncoupling protein (UCP-1, UCP-2, UCP-3) gene expression. Endocrinology (1998) 139:4920-7. doi:10.1210/endo.139.12.6384

182. Chavin KD, Yang SQ, Lin HZ, Chatham J, Chacko VP, Hoek JB, et al. Obesity induces expression of uncoupling protein-2 in hepatocytes and promotes liver ATP depletion. J Biol Chem (1999) 274:5692-700. doi:10.1074/jbc.274.9. 5692

183. Rashid A, Wu TC, Huang CC, Chen CH, Lin HZ, Yang SQ, et al. Mitochondrial proteins that regulate apoptosis and necrosis are induced in mouse fatty liver. Hepatology (1999) 29:1131-8. doi:10.1002/hep.510290428

184. Boss O, Muzzin P, Giacobino JP. The uncoupling proteins, a review. Eur J Endocrinol (1998) 139:1-9. doi:10.1530/eje.0.1390001

185. Diehl AM, Hoek JB. Mitochondrial uncoupling: role of uncoupling protein anion carriers and relationship to thermogenesis and weight control "the benefits of losing control". J Bioenerg Biomembr (1999) 31:493-506. doi:10.1023/A:1005452624640

186. Yang SQ, Lin HZ, Lane MD, Clemens M, Diehl AM. Obesity increases sensitivity to endotoxin liver injury: implications for the pathogenesis of steatohepatitis. Proc Natl Acad Sci U S A (1997) 94:2557-62. doi:10.1073/pnas.94.6.2557

187. Faggioni R, Fantuzzi G, Gabay C, Moser A, Dinarello CA, Feingold KR, et al. Leptin deficiency enhances sensitivity to endotoxin-induced lethality. Am J Physiol (1999) 276:R136-42.

188. Takahashi N, Waelput W, Guisez Y. Leptin is an endogenous protective protein against the toxicity exerted by tumor necrosis factor. J Exp Med (1999) 189:207-12. doi:10.1084/jem.189.1.207-a

189. Guarner C, Soriano G. Bacterial translocation and its consequences in patients with cirrhosis. Eur J Gastroenterol Hepatol (2005) 17:27-31. doi:10.1097/ 00042737-200501000-00006

190. Wiest R, Garcia-Tsao G. Bacterial translocation (BT) in cirrhosis. Hepatology (2005) 41:422-33. doi:10.1002/hep.20632

191. Amar J, Chabo C, Waget A, Klopp P, Vachoux C, Bermúdez-Humarán LG, et al. Intestinal mucosal adherence and translocation of commensal bacteria at the early onset of type 2 diabetes: molecular mechanisms and probiotic treatment. EMBO Mol Med (2011) 3:559-72. doi:10.1002/emmm.201100159

192. Ehses JA, Meier DT, Wueest S, Rytka J, Boller S, Wielinga PY, et al. Tolllike receptor 2-deficient mice are protected from insulin resistance and beta cell dysfunction induced by a high-fat diet. Diabetologia (2010) 53:1795-806. doi:10.1007/s00125-010-1747-3

193. Cani PD, Neyrinck AM, Fava F, Knauf C, Burcelin RG, Tuohy KM, et al. Selective increases of bifidobacteria in gut microflora improve high-fat-diet-induced diabetes in mice through a mechanism associated with endotoxemia. Diabetologia (2007) 50:2374-83. doi:10.1007/s00125-007-0791-0

194. Delzenne NM, Cani PD. Gut microbiota and the pathogenesis of insulin resistance. Curr Diab Rep (2011) 11:154-9. doi:10.1007/s11892-011-0191-1

195. De Bandt JP, Waligora-Dupriet AJ, Butel MJ. Intestinal microbiota in inflammation and insulin resistance: relevance to humans. Curr Opin Clin Nutr Metab Care (2011) 14:334-40. doi:10.1097/MCO.0b013e328347924a

196. Romeo J, Nova E, Wärnberg J, Gómez-Martínez S, Díaz Ligia LE, Marcos A. Immunomodulatory effect of fibres, probiotics and synbiotics in different lifestages. Nutr Hosp (2010) 25:341-9. doi:10.3305/nh.2010.25.3.4517

197. Mattace Raso G, Simeoli R, Iacono A, Santoro A, Amero P, Paciello O, et al. Effects of a Lactobacillus paracasei B21060 based synbiotic on steatosis, insulin signaling and toll-like receptor expression in rats fed a high-fat diet. J Nutr Biochem (2014) 25:81-90. doi:10.1016/j.jnutbio.2013.09.006 
Conflict of Interest Statement: The authors declare that the research was conducted in the absence of any commercial or financial relationships that could be construed as a potential conflict of interest.

Received: 31 January 2014; paper pending published: 02 April 2014; accepted: 04 April 2014; published online: 23 April 2014.

Citation: Meli R, Mattace Raso G and Calignano A (2014) Role of innate immune response in non-alcoholic fatty liver disease: metabolic complications and therapeutic tools. Front. Immunol. 5:177. doi: 10.3389/fimmu.2014.00177
This article was submitted to Inflammation, a section of the journal Frontiers in Immunology.

Copyright (c) 2014 Meli, Mattace Raso and Calignano. This is an open-access article distributed under the terms of the Creative Commons Attribution License (CC BY). The use, distribution or reproduction in other forums is permitted, provided the original author(s) or licensor are credited and that the original publication in this journal is cited, in accordance with accepted academic practice. No use, distribution or reproduction is permitted which does not comply with these terms. 